\title{
Adapting of (NANDA) Nursing Process as an Approach of Care for COVID-19 Isolated patients
}

\author{
Entisar, G. Shabaan ${ }^{1}$, Safaa M. Hamed ${ }^{2}$, Zahra A. Sayed ${ }^{3}$, Om Hashem G. Ragab ${ }^{4}$ \& Karima H. \\ Abdelhafez ${ }^{5}$. \\ 1. Associate Professor of Medical -Surgical Nursing, Faculty of nursing, Aswan University, Egypt. \\ 2. Lecturer of Medical -Surgical Nursing, Faculty of nursing, Banha University, Egypt. \\ 3. Lecturer of critical care Nursing, Faculty of nursing, Aswan University, Egypt. \\ 4. Lecturer of Nursing Administration Faculty of nursing, Sohag University, Egypt. \\ 5. Assistant professor of Nursing Administration, Faculty of Nursing, Assiut university, Egypt.
}

\begin{abstract}
The nursing process is a problem-solving framework that enables the nursing staff to plan their care for (COVID-19) patients. Aim: this study aims to evaluate the effect of adapting (NANDA) nursing process as an approach of Care on nurses' performance for COVID-19 Isolated patients. Design: Quasi experimental design was utilized to conduct this study. Setting: Isolation departments at Aswan University Hospital. Subjects: All nurses who are workers with (COVID-19) (17 males and 29 females) during the period from the beginning of April 1st 2020 to September 30th 2020. Tools :two tools used to collect the study data, Demographic data, nurses knowledge about COVID-19 and nursing' process application for nursing workers with (COVID-19) patients. Results: More than half of study sample's age group between $26<30$ years, females, no training on application of nursing process and half of them have institute education, three quarters of the study sample had satisfactory level of knowledge pre Adapting nursing process, while all study sample had satisfactory post application, highly significant results for total component of nursing process (assessment, diagnosis, planning, implementation, and evaluation) between pre/post Adapting application of nursing process for COVID-19 isolated patients. Also there are positive significant correlation between total component of nursing process and total knowledge post adapting application of nursing process for COVID-19 isolated patients. Conclusions: Results denotes that, improved level of nurses' knowledge post caring for COVID-19 Isolated patients by using steps of nursing process with highly statistical significant deference's for total components of nursing process pre/post application. Recommendations: The nursing staff and health care team must be continue educate on the application of the nursing process to emergency situation, nursing administration should develop effective departmental policies and procedures for staff nurses related to application (NANDA) nursing process as an approach of Care for COVID-19 Isolated patients.
\end{abstract}

\section{Keywords : Adapting, Approach of Care, COVID-19, NANDA \& Nursing Process.}

\section{Introduction}

Coronavirus disease 2019 (COVID-19) is one of the high incidence and spread internationally at the end of 2019. COVID-19 is the third coronavirus infection in two decades that was initially described in Asia. His testimony was given in Wuhan, China. As the epidemic continues to spread, it has been recorded by the World Health Organization (WHO, 2020) and registered as an international public health emergency (Dong, et al., 2020).

The signs of COVID-19 may be moderate and appear in as few as two days or to sever as two weeks after exposure. The described COVID-19 is rapid predictions to emergencies such as respiratory distress and pneumonia with high mortality (ANA., 2020; WHO., 2020). COVID-19 has a high infection, and droplet transmission and contact may lead to disease, first-line medical staff needs large amounts of standardized preventive evidence to care for this (Martin \& Bowden, 2020).
In 1958, Ida Jean Orlando initiated the North American Nursing Diagnosis Association (NANDA) nursing process that continues to guide nursing care today. The nursing process is an extensively accepted technique and has been recommended as a systematic way to guide procedures and efficiently nursing care. Recently, the nursing process defined as an organized and dynamic method to carry out nursing care, functional through 5 connected steps: nursing assessment, nursing diagnosis, planning of care, implementation plan and evaluation (Younan, et al., 2019).

Emergency patients with COVID-19 need a high standards level of nursing care. Thus, the establishment and application of nursing practice as a nursing process is a reference for clinical nursing care. This helps to efficiently organize and manage comprehensive nursing care for patients with COVID-19, improve their physical and psychological conditions, and enhance disease outcomes (Karttunen, et al., 2020). 
Nursing care centered on preserve the patient's life and prevents complications. Through, efficient continuous respiratory monitoring, continuous monitoring of vital signs, hemodynamic support, nutritional status, careful administration of medication to prevent progressive bad prognosis and close monitoring of fluid and electrolyte, gastrointestinal care, nursing care strategies should also include trials to prevent complications (Dong, et al., 2020).

According to current American and Canadian practice standards, nursing skills needs the competent use of the nursing process and qualified membership in activities that provide to the permanent progress of knowledge about this approach (Miskir \& Emishaw, 2018).

Care of patients with COVID-19 using high level quality of care standard based on patients' needs. Large importance for applied and using a systematic plan like (NANDA) nursing process to provision nursing care and estimating care time (ANA., 2020).

\section{Research significance}

Approximately 20 patients daily admitted to isolated Aswan university hospital, half of them admitted with emergency medical conditions and acute respiratory complicated patients with COVID-19 need special nursing care to rapid/early assessment and detection of complications, this through carrying out performance by using effective (NANDA) nursing process as intervention practice (Raso, et al., 2019). This study was providing the nurses knowledge and practice about, quickly patients' assessment, nursing diagnostic for COVID-19, current planning, nursing intervention/implementation, the end nursing evaluation. Also, training methods included face-toface training, practice, and lessons online. Videos, PPT, manuals booklet, and images were provided for nurses whenever possible.

\section{Aims of the Research}

This study aims to evaluate the effect of adapting (NANDA) nursing process as an approach of care on nurses' performance for COVID-19 isolated patients. This aim achieves through the following:

1. Assess nurses' knowledge, and practice about COVID-19 isolated patients

2. Designed statement application by using steps of (NANDA) nursing process as an approach of care for (COVID-19) isolated patients .

3. Evaluate the effect of implementing adapting (NANDA) nursing process on nurses' knowledge and practice for (COVID-19) isolated patients.

\section{Research hypothesis}

H1: Nurses working with COVID-19 isolated patients, attending to (NANDA) nursing process training will show improved level of knowledge, and practice post application than pre .
H2: Nurses working with COVID-19 isolated patients, attending to (NANDA) nursing process training will show positive correlation between knowledge, and practice post application.

\section{Subjects and Method}

\section{Research design}

Pre /posttest quasi experimental design was utilized to conduct this study .

\section{Setting}

The study was conducted in emergency department containing (14 beds), medical department containing ( 25 beds), chest department containing ( 20 beds) and intensive care unit (ICU) containing (12 beds) at the Aswan University Hospital. The patient come to this hospital who is suffering from COVID-19 and respiratory problems.

\section{Subjects}

Convenience sample of (17 males and 29 female) nurses he/she were completed the online tools, age ranges from 18 to 60 years and don't have any training program about application of nursing process for (COVID-19) patients. All nurses who are workers with (COVID-19) patients at isolation hospital.

\section{Methods:}

\section{All nurses were subjected to}

Tools of the study

Two tools were utilized to collect data for this study: The literature review was searched and seek by research plain through using the following key words (emergency ward, surgical ward, nursing process, assessment, diagnoses, planning, intervention and evaluation or expected out com).

Tool I : This tool consists of two parts :Part I: Socio demographic data for nurses. Part II: Knowledge about (COVID-19).

Part I : Socio demographic data for nurses as (age, gender, level of education \& years of experience, attained training in the field of specialization, nursing process, benefit from attending training courses. It includes 7 items).

Part II :Nurses' knowledge about COVID-19 Pre/posttest :It was constructed by the researcher based on current World Health Organization, (2020). To assess their knowledge about COVID-19, definition, manifestation, diagnoses, complications, personal protective, infection control measures and level of prevention. That includes total (25 questions). It was used prior to application of the nursing process to measure the exact knowledge level of nurses regarding COVID-19, The same tool was used (immediate post -test). The questionnaire sheet was administered by the researcher to the nurses for answering all its components then collected.

Scoring system: Knowledge obtained from nurses was scored and calculated. Each question ranged 
from 0-2 grade. Whereas the correct answer scored 2 grades and scored zero for an incorrect answer. The total score level for the questionnaire sheet was 50 grades (equal 100\%).

- Knowledge scores > 75\% considered satisfactory knowledge.

- The nurses' knowledge $<75 \%$ considered unsatisfactory

knowledge.

Tool II: Statement adopted and modified by the researchers, then, to form steps of (NANDA) nursing process application for nurses' workers with (COVID-19) patients :this part was adapted from Wang et al, (2019); National Health Commission of the People's Republic of China, (2020); WHO., (2020) \& Jin et al, (2020) and modified by the researchers based on relevant recent reviewing of literature, it includes five steps (patients' assessment (11 elements), clinical diagnostic, criteria for COVID-19 (11 elements), current planning (12 elements), nursing intervention and treatment regimens the end (13elements), evaluation of the patient prognoses (11 elements), totally 58 elements. Each item in element is graded on a 3 point $(0=$ never, $1=$ some times and $2=$ always).

\section{Nursing Assessment}

Assessing Medical history

1. History of living in the epidemic area, and comorbidities.

2. Assessing past medical history

3. Treatment history.

Physical assessment:

1. Assessing the patient's vital signs :

a. Body temperature.

b. Blood pressure.

c. Pulse.

d. Blood oxygen saturation.

e. Breathing rate rhythm and depth; etc .

Assessing the patient's signs and symptoms.

a. Level of consciousness. b. Muscle pain.

c. Fatigue (Tongji Hospital Affiliated with Tongji

Medical College of Huazhong University of

Science and Technology, 2020).

Assessing respiratory system:

a.Cough, sputum. b. Chest tightness.

c. Shortness of breath. d. Dyspnea.

e. O2 saturation.

f. ABG. (Chinese

Preventive Medicine Association, 2020).

Assessing gastro intestinal system (GIT):

a. Diarrhea. b. Abdominal pain. c. Vomiting. d. Constipation.

Assessing Nourishing condition

a. Assess the ability of the patients to diet intake.

b. Assessing skin and mucosa membrane, skin color and elasticity, or dehydration, etc.
Assessing peripheral extremity circulation:

a. Presence of bleeding, etc.

Assessing patients' psychological state

a. Assessing emotional response to the disease.

b. Cognitive changes.

c. Patients compliance with protective measures.

Assessing environmental whether risks of crossinfection exist.

Ensuring and assessing adequate bed spacing and the negative pressure ward.

Ensuring protective measures for high-risk operations and adequate personal protective measures for both patients and medical staff (Jin, et al., 2020).

Nursing diagnosis: Priority health problems:

1. Impaired gas exchange related to increased airway resistance and decreased lung compliance.

2. Hyperthermia related to viral lung infection and diseases.

3. Activity intolerance related to impaired lung function and imbalanced oxygen supply and consumption.

4. Risk for dehydration related to diarrhea.

5. Potential complications, deep vein thrombosis, hyperglycemia, acute respiratory distress syndrome, septic shock, metabolic acidosis, coagulopathy, multiple organs dysfunction syndrome, stress ulcers, etc.

6. Anxiety/fear e related to isolation and concerns over the disease's prognosis

Other health problems

1. Ineffective airway clearance related to excessive secretion and ineffective cough.

2. Diarrhea related to intestinal movement dysfunction due to COVID-19 infection.

3. Impaired comfort e related to disease-related signs, such as fatigue, chest tightness and gasping breaths.

Imbalanced nutrition: less than body requirements related to hyperthermia, diarrhea, reduced intake, loss appetite etc.

4. Risk for loss skin integrity related to fever, reduced peripheral circulation, and required position.

5. Knowledge deficit patients may have inadequate knowledge related to isolation measure, personal protection and COVID-19 process.

Nursing Plan of care

1. Relieving dyspnea and improve oxygenation. Ensuring effective coughing.

2. Breathing becoming regular and stable and clear lung sounds.

3. Effectively controlling body temperature.

4. Minting sufficient intake to relieving diarrhea and improve bowel movement.

5. Reducing the risk of pressure ulcer during hospitalization. 
6. Early detection and control complications efficiently.

7. Reassuring patients to stable emotional condition and gaining patients cooperation when implementing nursing interventions.

8. Ensuring a gradual return to a normal diet and preserving the desired body weight.

9. Improving patient comfort during hospitalization and satisfying their demand.

10. Improving patients' activity daily living.

11. Ensuring high level standard with isolation and effective self-protective measure among patients (Chinese Preventive Medicine Association, 2020).

Nursing interventions

Providing optimum oxygen therapy and respiratory support

1. Accurately evaluating respiratory distress or desaturation (National Health Commission of the People's Republic of China, 2020).

2. Patients under nasal cannula oxygen therapy can wear face mask to diminish the spread of viral aerosols (Respiratory Critical Care Medicine Group of the Respiratory Medicine Branch of the Chinese Medical Association, 2020).

3. Patients connecting to invasive mechanical ventilator, apply low inspiratory pressure) plateau pressure $<30 \mathrm{cmH} 2 \mathrm{O}$ to reduce ventilatorinduced lung injury and a small tidal volume (National Health Commission of the People's Republic of China, 2020).

4. Closely monitoring patients' breathing characteristics (rate, rhythm, depth, frequency, spontaneous breathing trail and ventilator), close monitoring arterial blood gas and oxygen saturation (Ge H, 2020).

5. Passively humidify invasive mechanical ventilators using a heat-moisture-exchanger with a bacterial filter to reduce concentration in the circuit (Wang et al, 2020).

6. Using of one-use ventilator circuits, Exchange filters only upon contamination (Wang et al, 2020).

7. Ventilator disconnected, use $75 \%$ alcohol to disinfect the surface of the ventilator machine.

8. Reusable catheters must be immersion for $30 \mathrm{~min}$ in $1,000 \mathrm{e} 2,000 \mathrm{mg} / \mathrm{L}$ of chlorine-containing disinfectant after that send to the disinfection center for sterilization and deal with disposable catheters as infectious medical waste.

9. Application of prone position ventilation for more than twelve hours per day (National Health Commission of the People's Republic of China, 2020).

10. Before implementing prone ventilation, suctioning secretions should be performed
11. Suctioning stomach contents before prone ventilation and provide feeding in small amounts.

12. Establishing decompression dressings to pressured areas to diminish potential skin injuries.

13. Elevating head of the bed 45 degree to Prevent ventilator-associated pneumonia (VAP) (Infectious Diseases Group of the Respiratory Medicine Branch of the Chinese Medical Association, 2018).

14. Careful checking and minting the cuff pressure of the endotracheal tube at $25 \mathrm{e} 30 \mathrm{cmH} 2 \mathrm{O}$ to prevent tracheal ulcer (Ni Z, Qin et al., 2020).

Maintaining an airway clear

1. Educating patients to perform effective coughing in plastic bag when expectorate to prevent spreading the virus andperform breathing exercise.

2. Using a closed system of endotracheal suctioning to aspirate secretions and improve oxygenation (Chinese Preventive Medicine Association, 2020).

Hyperthermia nursing care

1. Offer antipyretic therapy as prescribed and assessing patient response.

2. Closely monitoring body temperature, sweating, skin turgor, fluid and electrolyte balance.

3. Dry patients', change clothes and sheets of the bed when patient heavy sweating .

4. Treating polluted clothes and sheets as infective fabrics and put them into yellow waste bags.

5. Encouraging patient's fluid intake, and report intake and output (Regulation for washing and disinfection technique of medical textiles in healthcare facilities, 2016).

Special care

Nursing care for patients with blood purification therapy

1. Central venous catheterization, strictly implementing maximum aseptic techniques and protective measures (American Society of Anesthesiologists, 2020).

2. Monitoring vital signs and evaluate the patency of vascular access.

3. Closely monitoring patients' vital signs, coagulation functions, electrolyte changes, and treatment response (Expert Team of Chinese Medical Association Nephrology Branch, 2020).

Nursing care for patients with convalescent plasma therapy

1. Confirming that patients sign an informed consent form.

2. Strictly follow aseptic process procedures and blood transfusion technical specific actions. 
3. During therapy, especially within the first $15: 20$ min of the transfusion, closely monitor vital signs and skin changes.

4. Intravenously-hydrocortisone and anti-allergy amble should be giving to avoid sensitivity reaction.

5. Transfusion convalescing plasma gradually within 1: 4 hours (Expert Team of Chinese Medical Association Nephrology Branch, 2020).

6. After treatment is accomplished, discard blood bags in double layer yellow medical waste bags instead of recycling them (Expert Team of Chinese Medical Association Nephrology Branch, 2020).

7. Evaluate the effectiveness of the therapy session.

Monitoring and nursing care for administration drug

1. Dexamethasone and hydrocortisone are both corticosteroids; have role in treating COVID-19

- Dexamethasone given orally (tablet) one three time/ day.

- Intravenously-hydrocortisone can be given intravenously (Ampule) or intramuscular (World Health Organization, 2020).

2. Administer drugs according to medical prescription.

3. Pay attention to drug contraindications (National Health Commission of the People's Republic of China, 2020).

4. When medicine injection is used in conjunction, flush the catheter with normal saline.

5. Distinct administration of intestinal micro ecological regulators by two hours from antibiotics administration.

6. Closely monitor adverse drug reactions.

7. Regularly monitoring patients' gastrointestinal responses. Offer supplementary Vitamin D and calcium and regularly monitor calcium concentration in the blood.

8. Administering bowel micro ecological regulators with warm water (Committee of Critical Care Medicine, Chinese Association of Chest Physician, Chinese Medical Doctor Association, 2019).

Nursing action for catheter:

1. Confirming that all catheters are open and free from any obstruction, securely connected, and fixed firmly to avoid shifting and falling.

2. Closely monitoring the property, and quantity of the drainage fluid.

3. Strictly follow disinfection regulations to avoid secondary infections.

4. Discard polluted drainage bottles and bags in twofold layer yellow medicinal waste bags and dispose of them in accordance hospital policies
(Regulation for washing and disinfection technique of medical textiles in healthcare facilities, 2016).

Monitoring patients' conditions

1. Carefully monitoring vital signs especially breathing rate, rhythm, pattern, and depth.

2. Performing hemodynamic monitoring to detect arrhythmia and heart failure or electrolyte imbalance (National Health Commission of the People's Republic of China, 2020).

3. Recording patients' intake and output within 24 hours to maintain water, electrolyte, and acid-base balances.

4. Careful monitoring of infection indicators and collect blood, sputum, urine, stool, and other specimens promptly and correctly.

5. Early detecting complications, exacerbation develop symptoms such as persistent high fever, respiratory failure, shock, or multiple organs failure (Ma Jet al, 2020).

Food and nutrition

For patients with oral food intake

1. Ensuring oxygen supply is not disconnected during drinking or eating.

2. Patients should have small frequent meals, with a diet predominantly composed of eggs, dairy products, fruit juice, vegetable juice, and so on.

Enteral nutrition support

1. Enteral nutrition for patients unable to orally intake at least $60 \%$ of their energy consumption (Xu, et al., 2020).

2. Monitoring nutrition indicators, including albumin, transferrin, and pre-protein counts.

3. During enteral nutrition infusion, elevate the head of bed at an angle 30 to prevent accidental aspiration (Chen, 2020).

Parenteral nutrition support.

1. Parenteral nourishment is necessary for patients with severe digestive disorder.

2. Closely monitoring any change of metabolic status and progressive complications (Xu et al, 2020).

Basic nursing care

Skin care

1. Closely monitoring facial skin for any pressure ulcer during oxygen therapy resulting from intubation and face mask.

2. Encouraging patients change position regularly to prevent skin damage (Chinese Health Education Center, National Health Commission Ministry of Publicity, 2020).

Oral care

1. Patients who can do self-care must be encouraged to perform oral care.

2. Performing oral care 2 or 3 times per day for patient who cannot care for themselves. 
3. During performing oral care for patients, potential splash of secretions nurses should wear Level III personal protection equipment (World Health Organization, 2020).

Elimination care

Treating Diarrhea

1. Assessing for abdominal discomfort, pain, cramping, frequency, urgency, loose or liquid stools, and hyperactive bowel sensations.

2. Replacing fluid \& electrolytes: Pedialyte.

3. Bedpans should be used totally for each patient. After use, immerse the bedpan in a disinfectant solution containing $5,000 \mathrm{mg} / \mathrm{L}$ of effective chlorine and then clean it for reuse (Regulation for washing and disinfection technique of medical textiles in healthcare facilities, 2016).

4. Protecting the skin by lubricant.

5. Inquire about: Tolerance to milk and other dairy products.

6. Culture stool.

7. Anti-diarrheal medications.

Preventing constipation

1. Diet should be containing fibers.

2. Maintaining adequate fluid intake and soft diet.

3. Ensuring movement and Exercise.

4. Laxatives \& enemas administration if needed (National Health Commission of the People's Republic of China, 2020).

Patients Psychological care

1. Orienting patients to the health care setting and isolation protocols upon admission.

2. Regulating assessing psychological condition and encourage patients to express feeling.

3. Providing emotional support and helping them to build confidence in their ability to overwhelm the illness.

5. Help to link information with out of hospital relatives (National Health Commission of the People's Republic of China, 2020).

\section{Early respiratory rehabilitation}

1. Assessing the viability of respiratory rehabilitation programs for patients in ward or within ICU.

2. Offer instructional: Videos, brochures, etc.

3. Rehabilitation within health care setting include changes in body position, abdominal breathing and pursed-lip breathing; effective sputum expectoration techniques such as postural drainage and effective coughing to promote oxygenation and maintain an unobstructed airway

(Wang, et al., 2019).

Rest and physical activities

1. Adequate sleep, sleep disorders should be managing by drugs as medical prescribed.

2. Mobilization recommendation (lie in the bed for 30 secs, drop both legs for $30 \mathrm{sec}$ before standing up, and stand for $30 \mathrm{sec}$ before walking) (Wang, et al., 2019).

3. Perform passive and active range of motion according patient condition and tolerance (Tan, et al., 2017).

Discharge instructions

1. Educating patients to performing respiratory rehabilitation actions.

2. Ensuring timely transmission of patients to the designated place for centralized isolation of two weeks (National Health Commission of the People's Republic of China, 2020).

3. Informing patients to make follow-up visit after discharge.

4. Instructing patients to maintain adequate sleep, a balanced diet, and a calm emotional state.

5. Educating patients to perform hand hygiene and wearing mask, maintain distance from other members (Chinese Preventive Medicine Association, 2020).

Nursing Evaluation: includes evaluating the following:

1. Patient health improvement.

2. Application of nursing care plain.

3. Nursing care from time to time.

4. Nurse experience for nursing care.

5. Record all the nursing care steps.

6. Patient was able to prevent the spread of infection.

7. Patient was able to learn more about the disease and its management.

8. Patient was able to improve body temperature levels.

9. Patient was able to restore breathing pattern back to normal.

10. Patient was able to reduce anxiety.

11. Teaching plan.

Scoring system

The total score ranging from 0 to 114 , with higher scores indicating always

Score $\leq 38$ indicating never do.

Score range from 39-77 indicating sometime does.

Score range from 78-114 always does.

Data Collection Technique

This study was carried out in three phases :

Phase I: (preparatory phase): assessment and planning phase (involved the following; review of relevant literature: nursing textbooks, journals, internet resources about COVID-19, in selected sittings. Then content and construct validity for data collection tools were carried out. Based on findings of the assessment, the five components of nursing process were developed, after extensive literature review considering nurses needs and their level of understanding . 


\section{Phase II :Implementation phase}

This study was carried out through a period of six months from April $1^{\text {st }} 2020$ to September $30^{\text {th }} 2020$. Data were collected from medical, Emergency departments and ICU unit at Aswan university hospital. The study was carried out at morning, and afternoon shifts.

- Firstly, the researchers purpose of the study was explained to the nurses orally prior to answering the questions and fill out the questionnaire sheet) tool I ( to assessing nurse's knowledge before application of the nursing process available at Google drive by this

link https//:docs.google.com/forms/d/e/1FAIpQLScTImt oQ3WxYshqp6A_ievbkZtrRjw3AzogB2MrpIMw MqG6Q/viewform?usp=sf link.

- Then, the data collected by using E -learning methods and internet) Google drive. (The researchers translated the observation checklist into Arabic language) tool II part II (and available at Google drive by this link https//:docs.google.com/forms/d/e/1FAIpQLScTImt oQ3WxYshqp6A_ievbkZtrRjw.3AzogB2MrpIMw MqG6Q/viewform?usp=sf_link .

- Each training usually started by a summary of what has been taught during the previous lectures and the objectives of the new topics. Feedback and reinforcement of intervention of nursing process was performed according to the nurses needs to ensuring their understanding .

- Interviewing of studied nurses was conducted according to their available time in (morning, evening, and night shift) to collect data. Indirect observation for nursing practice regarding COVID19 was done individually for each nurse. The time needed for observing each nurse ranged from 4-6 hours. Only one nurse observed per day.

- Each nurses obtained a copy of the component steps of nursing process, the training methods included observation completed by head nurses at selected sittings, practice, and lessons online. Videos, PPT, manuals booklet, and images were provided for nurses whenever possible .

- This booklet is in Arabic Langue The objective of this booklet was to improve knowledge, information and practices after application of nursing process .It consists of the following; knowledge related to COVID-19, Also, reassessment post intervention the nursing skills and practices regarding of steps of nursing process tool II part II by observation checklist by this link https//:docs.google.com/forms/d/e/1FAIpQLScTImt
oQ3WxYshqp6A_ievbkZtrRjw3AzogB2MrpIMw MqG6Q/viewform?usp=sf_link.

\section{Phase III :Evaluation Phase}

The last phase of application of nursing process is the evaluation phase .Immediately after implementation nurses' knowledge and practices has been evaluated by the researcher through filling the tool. Tool 1: (self-administered questionnaire sheet) 2: (steps of nursing process) 3: (evaluation tool).

\section{Administrative design}

An Approval to carry out this study was obtained from the dean of faculty of nursing and the director of selected setting at Aswan University Hospital.

\section{Statistical design}

Statistical analysis was done by using Statistical Package for Social Sciences (SPSS) version 20. Data were collected, revised, coded, organized, tabulated, and analyzed using frequencies, number, percentage and correlation coefficient. Qualitative data was presented in the form of frequency distribution tables, number and percent. It was analyzed by Chi- square test $\left(\mathrm{X}^{2}\right) \&$ correlation to detect the relation between the variables of the study ( $\mathrm{P}$ - value).

Statistical significance was considered as follows

$\mathrm{P}$ - value $>0.05 \quad$ Not significant

$\mathrm{P}$ - value $<0.05$ Significant

$\mathrm{P}$ - value $<0.001$ Highly significant

\section{Content validity}

It was established by panel of 5 expertise who reviewed the tools for clarity, relevance, comprehensiveness, understanding, applicability for pilot study and easiness for administration minor modifications were required.

\section{Reliability}

of proposed tools was done by Cronbach alpha test (0.750); the developed tools were tested using test retest method within 2 weeks .

\section{A pilot study}

Carried out in April 2020 to evaluate the clarity and applicability of the study tools on $10 \%$ of the sample. It had also provided an estimate of needed time to fill out the tools. The nurses who participated in the pilot study were all included in the study sample.

\section{Ethical considerations}

This study conducted after primary approval obtained from the Ethics Committee, faculty of nursing. Then official permission was obtained from the director of the isolation departments at Aswan University hospital. Study purpose explained to participants, and they also informed that they could withdraw from the study at any time before the completion of the study. 


\section{Results}

Table (1): Frequency and percentage distribution of the studied nurses related to their socio -demographic characteristics $(n .=46)$.

\begin{tabular}{|c|c|c|}
\hline Socio-demographic characteristics & $\mathbf{N}$ & $\%$ \\
\hline \multicolumn{3}{|l|}{ Age (Years) } \\
\hline $20<25$ & 7 & 15.5 \\
\hline $26<30$ & 29 & 63 \\
\hline $31 \leq 35$ & 10 & 21.7 \\
\hline \multicolumn{3}{|l|}{$\begin{array}{ll}\text { Mean } \pm \text { SD } & 28.93 \pm 4.59\end{array}$} \\
\hline \multicolumn{3}{|l|}{ Gender : } \\
\hline Male & 17 & 37 \\
\hline Female & 29 & 63 \\
\hline \multicolumn{3}{|l|}{ Training on application of nursing process: } \\
\hline Yes & 14 & 30.4 \\
\hline No & 32 & 69.8 \\
\hline \multicolumn{3}{|l|}{ Years of experience in nursing: } \\
\hline$<5$ Years & 22 & 47.8 \\
\hline 5-10 Years & 24 & 52.2 \\
\hline \multicolumn{3}{|l|}{ Mean \pm SD $1.52 \pm .505$} \\
\hline \multicolumn{3}{|l|}{ Education level: } \\
\hline Diploma Nursing & 20 & 43.5 \\
\hline Institute & 24 & 52.2 \\
\hline Bachelor & 2 & 4.3 \\
\hline \multicolumn{3}{|l|}{ Place of Work } \\
\hline Medical Ward & 14 & 30.4 \\
\hline Chest Ward & 7 & 15.2 \\
\hline ICU & 25 & 54.3 \\
\hline \multicolumn{3}{|l|}{ Work time } \\
\hline Day & 26 & 56.5 \\
\hline Afternoon & 20 & 43.5 \\
\hline
\end{tabular}

Table(2): Distribution of total knowledge score of nurses' regarding COVID-19 pre/post application of adapting nursing process $(n .=46)$.

\begin{tabular}{|l|c|c|c|c|c|c|}
\hline \multicolumn{1}{|c|}{ Total knowledge } & \multicolumn{2}{|c|}{$\begin{array}{c}\text { Pre application of adapting } \\
\text { nursing process }\end{array}$} & \multicolumn{2}{c|}{$\begin{array}{c}\text { Post application of } \\
\text { adapting nursing process }\end{array}$} & \multirow{2}{*}{$\mathbf{X}^{\mathbf{2}}$} & \multirow{2}{*}{ P-value } \\
\hline & $\mathrm{N}$ & $\mathbf{\%}$ & $\mathrm{N}$ & $\mathbf{\%}$ & & \\
\hline Un satisfactory & $\mathbf{1 2}$ & 26.1 & - & - & \multirow{2}{*}{42.094} & \multirow{2}{*}{$\mathbf{0 . 0 0 1 * *}$} \\
\hline Satisfactory & $\mathbf{3 4}$ & $\mathbf{7 3 . 9}$ & $\mathbf{4 6}$ & $\mathbf{1 0 0 \%}$ & \\
\hline
\end{tabular}

NB: Significant $<0.05, *$ highly statistically significant at $\leq 0.001 * *$ 
Table (3) : Distribution of the nurses' practice in elements of assessment pre/post application of adapting nursing process for COVID-19 isolated patients. $(\mathrm{n}$. $=$ 46)

\begin{tabular}{|c|c|c|c|c|c|c|c|c|c|c|c|c|c|c|}
\hline \multirow{3}{*}{ The elements of assessment. } & \multicolumn{6}{|c|}{ Pre application of adapting nursing process } & \multicolumn{6}{|c|}{ post application of adapting nursing process } & \multirow{2}{*}{\multicolumn{2}{|c|}{ Significance test }} \\
\hline & \multicolumn{2}{|c|}{ Always } & \multicolumn{2}{|c|}{ Sometimes } & \multicolumn{2}{|c|}{ Never } & \multicolumn{2}{|c|}{ Always } & \multicolumn{2}{|c|}{ Sometimes } & \multicolumn{2}{|c|}{ Never } & & \\
\hline & $\mathbf{N}$ & $\%$ & $\mathbf{N}$ & $\%$ & $\mathbf{N}$ & $\%$ & $\mathbf{N}$ & $\%$ & $\mathbf{N}$ & $\%$ & $\mathbf{N}$ & $\%$ & $\mathbf{X}^{2}$ & $\begin{array}{c}\text { P- } \\
\text { value }\end{array}$ \\
\hline Assessment of medical history. & 20 & 43.5 & 16 & 34.8 & 10 & 21.7 & 39 & 83.0 & 4 & 8.5 & 4 & 8.5 & 10.017 & $0.040 *$ \\
\hline $\begin{array}{l}\text { Physical assessment: } \\
\text { - Assessing the patient's vital sings. }\end{array}$ & 40 & 87.0 & 6 & 13.0 & - & - & 46 & 100.0 & - & - & - & - & 46.35 & 0.620 \\
\hline - Assessing the patient's Symptoms and signs- & 34 & 73.9 & 12 & 19.0 & -- & - & 40 & 87.0 & 6 & 13.0 & - & - & 37.47 & 0.593 \\
\hline - Assessing the patient's skin and mucosa- & 21 & 45.7 & 20 & 43.5 & 5 & 10.9 & 36 & 78.3 & 9 & 19.6 & 1 & 2.2 & 23.71 & 0.029* \\
\hline - Assessing the patient's nutritional status- & 28 & 60.9 & 11 & 23.9 & 7 & 15.2 & 36 & 78.3 & 5 & 10.9 & 6 & $\begin{array}{l}12 . \\
8.0\end{array}$ & 14.60 & $\begin{array}{c}<0.05 \\
*\end{array}$ \\
\hline $\begin{array}{l}\text { Psychological assessment: } \\
\text { - Assessing the patient's emotional response to } \\
\text { the disease, }\end{array}$ & 10 & 21.7 & 24 & 52.2 & 12 & 26.1 & 38 & 80.9 & 8 & 17.4 & - & - & 6.285 & 0.043* \\
\hline $\begin{array}{l}\text {-Assessing cognitive changes, and compliance } \\
\text { with protective measures. }\end{array}$ & 32 & 69.6 & 8 & 17.4 & 6 & 13.0 & 40 & 87.0 & 4 & 8.7 & 2 & 4.3 & 22.56 & 0.013* \\
\hline $\begin{array}{l}\text { Environmental assessment : } \\
\text { Assessing environmental risks of cross-infection } \\
\text { exist. }\end{array}$ & 31 & 67.4 & 15 & 32.6 & - & - & 41 & 87.5 & 6 & 12.8 & - & - & 14.673 & $\begin{array}{c}<0.05 \\
*\end{array}$ \\
\hline $\begin{array}{l}\text {-Assessing adequate bed spacing and the } \\
\text { negative pressure ward, protective measures. }\end{array}$ & 29 & 63.0 & 12 & 26.1 & 5 & 10.9 & 38 & 80.9 & 8 & 17.4 & - & - & 24.77 & 0.239 \\
\hline $\begin{array}{l}\text {-Assessing protective measures for high-risk } \\
\text { operations . }\end{array}$ & 35 & 67.0 & 11 & 23.9 & - & - & 41 & 87.5 & 5 & 10.9 & - & - & 62.35 & 0.730 \\
\hline $\begin{array}{l}\text {-Assessing adequate personal protective } \\
\text { measures for both patients and medlical staff. }\end{array}$ & 30 & 67.9 & 9 & 16.9 & 7 & 15.2 & 46 & 100.0 & - & - & - & - & 60.60 & 0.041* \\
\hline
\end{tabular}

NB: Significant $<0.05,{ }^{*}$ highly statistically significant at $\leq 0.001^{* *}$ 
Table (4): Distribution of the nurses' practice in elements of diagnosis pre/post application of adapting nursing process for COVID-19 isolated patients (n. $=46)$.

\begin{tabular}{|c|c|c|c|c|c|c|c|c|c|c|c|c|c|c|}
\hline \multirow{3}{*}{ The elements of Diagnosis } & \multicolumn{6}{|c|}{ Pre application of adapting nursing process } & \multicolumn{6}{|c|}{ post application of adapting nursing process } & \multirow{2}{*}{\multicolumn{2}{|c|}{ Significance test }} \\
\hline & \multicolumn{2}{|c|}{ Always } & \multicolumn{2}{|c|}{ Sometime } & \multicolumn{2}{|c|}{ Never } & \multicolumn{2}{|c|}{ Always } & \multicolumn{2}{|c|}{ Sometime } & \multicolumn{2}{|c|}{ Never } & & \\
\hline & $\mathbf{N}$ & $\%$ & $\mathbf{N}$ & $\%$ & No. & $\%$ & $\mathbf{N}$ & $\%$ & $\mathbf{N}$ & $\%$ & $\mathbf{N}$ & $\%$ & $\mathbf{X}^{2}$ & P-value \\
\hline $\begin{array}{l}\text { 1.Impaired gas exchange e related to increased } \\
\text { airway resistance and decreased lung compliance }\end{array}$ & 1 & 2.2 & 35 & 76.1 & 10 & 21.7 & 28 & 59.6 & 19 & 41.3 & - & - & 2.816 & 0.245 \\
\hline 2.Hyperthermia e related to viral lung infection & 19 & 41.3 & 17 & 37.0 & 10 & 21.7 & 27 & 57.4 & 13 & 27.7 & 7 & 14.9 & 10.47 & $\mathrm{0.033}^{*}$ \\
\hline $\begin{array}{l}\text { 3. Activity intolerance e related to impaired lung } \\
\text { function and imbalanced oxygen supply and } \\
\text { consumption. }\end{array}$ & 22 & 47.8 & 15 & 32.6 & 9 & 19.6 & 36 & 76.6 & 11 & 23.4 & - & - & 1.498 & 0.475 \\
\hline $\begin{array}{l}\text { 4.High risk for dehydration, deep vein thrombosis, } \\
\text { hyperglycemia, acute respiratory distress } \\
\text { syndrome, septic shock, metabolic acidosis, etc. }\end{array}$ & 35 & 76.1 & 11 & 23.4 & - & - & 40 & 87.0 & 3 & 6.5 & 3 & 6.5 & 10.88 & 0. 027* \\
\hline $\begin{array}{l}\text { 5. Anxiety/fear e related to isolation and concerns } \\
\text { over the disease's prognosis. }\end{array}$ & 6 & 13.0 & 24 & 51.2 & 16 & 34.8 & 38 & 80.9 & 7 & 14.9 & 2 & 4.3 & 5.733 & $0.020 *$ \\
\hline $\begin{array}{l}\text { 6. Ineffective airway clearance e related to } \\
\text { excessive mucus and ineffective cough. }\end{array}$ & 14 & 30.4 & 26 & 56.5 & 6 & 13.0 & 36 & 76.6 & 9 & 19.1 & 2 & 4.3 & 2.854 & 0.583 \\
\hline $\begin{array}{l}\text { 7. Diarrhea related to intestinal dysfunction due to } \\
\text { COVID-19 infection. }\end{array}$ & 22 & 47.8 & 23 & 50.1 & 1 & 2.2 & 33 & 70.2 & 14 & 29.8 & - & - & 14.33 & $<0.05 *$ \\
\hline $\begin{array}{l}\text { 8. Impaired comfort related to illness-related } \\
\text { symptoms, such as chest tightness, gasping breaths } \\
\text { and fatigue. }\end{array}$ & 21 & 45.7 & 18 & 39.1 & 7 & 15.2 & 40 & 87.0 & 4 & 8.7 & 2 & 4.3 & 9.46 & $<0.05^{*}$ \\
\hline $\begin{array}{l}\text { 9. Imbalanced nutrition: less than body } \\
\text { requirements e related to fever, diarrhea, reduced } \\
\text { intake, etc. }\end{array}$ & 12 & 26.1 & 27 & 58.7 & 7 & 15.2 & 38 & 80.9 & 8 & 19.1 & - & - & $\begin{array}{c}11.28 \\
5\end{array}$ & $0.024 *$ \\
\hline $\begin{array}{l}\text { 10.Risk for impaired skin integrity e related to } \\
\text { fever, humidity, poor peripheral circulation, and } \\
\text { forced position }\end{array}$ & 17 & 37.0 & 17 & 37.0 & 12 & 26.1 & 30 & 63.8 & 11 & 23.4 & 6 & 12.8 & 11.36 & $0.023 *$ \\
\hline $\begin{array}{l}\text { 11. Knowledge deficit e patients may have } \\
\text { insufficient knowledge related to isolation concept, } \\
\text { personal protection and COVID-19. }\end{array}$ & 30 & 65.2 & 10 & 21.0 & 6 & 13.0 & 41 & 89.1 & 3 & 6.5 & 2 & 4.3 & 9.507 & $<0.05 *$ \\
\hline
\end{tabular}

NB: Significant $<0.05,{ }^{*}$ highly statistically significant at $\leq 0.001$ 
Table (5): Distribution of the nurses' practice in elements of planning pre/post application of adapting nursing process for COVID-19 isolated patients $(\mathrm{n}=\mathbf{4 6})$.

\begin{tabular}{|c|c|c|c|c|c|c|c|c|c|c|c|c|c|c|}
\hline \multirow{3}{*}{ The elements of Planning } & \multicolumn{6}{|c|}{ Pre application of adapting nursing process } & \multicolumn{6}{|c|}{$\begin{array}{c}\text { post application of adapting nursing } \\
\text { process }\end{array}$} & \multirow{2}{*}{\multicolumn{2}{|c|}{ Significance test }} \\
\hline & \multicolumn{2}{|c|}{ Always } & \multicolumn{2}{|c|}{ Sometime } & \multicolumn{2}{|c|}{ Never } & \multicolumn{2}{|c|}{ Always } & \multicolumn{2}{|c|}{ Sometime } & \multicolumn{2}{|c|}{ Never } & & \\
\hline & $\mathbf{N}$ & $\%$ & $\mathbf{N}$ & $\%$ & $\mathbf{N}$ & $\%$ & $\mathbf{N}$ & $\%$ & $\mathbf{N}$ & $\%$ & $\mathbf{N}$ & $\%$ & $\mathbf{X}^{2}$ & P-value \\
\hline 1. Relieving dyspnea and improve oxygenation. & 20 & 43.5 & 19 & 41.3 & 7 & 15.2 & 33 & 70.2 & 6 & 13.0 & 7 & 15.2 & 9.36 & $<0.05 *$ \\
\hline $\begin{array}{l}\text { 2. Ensuring effective coughing, breathing } \\
\text { becoming regular and stable and clear lung sounds. }\end{array}$ & 16 & 34.8 & 17 & 37.0 & 13 & 28.3 & 35 & 76.8 & 8 & 17.4 & 3 & 6.5 & 4.386 & 0.356 \\
\hline 3. Effectively controlling body temperature. & 20 & 43.5 & 22 & 47.8 & 4 & 8.7 & 40 & 87.0 & 6 & 13.0 & - & - & 2.266 & 0.322 \\
\hline $\begin{array}{l}\text { 4. Minting sufficient intake to relieving diarrhea } \\
\text { and improving bowel movement. }\end{array}$ & 6 & 13.0 & 40 & 87.0 & - & - & 37 & 80.4 & 9 & 19.6 & - & - & 9.69 & $0.046^{*}$ \\
\hline $\begin{array}{l}\text { 5. Reducing the risk of pressure ulcer during } \\
\text { hospitalization. }\end{array}$ & 13 & 28.3 & 25 & 53.2 & 8 & 17.4 & 40 & 87.0 & 6 & 13.0 & - & - & 13.70 & $<0.001 * *$ \\
\hline $\begin{array}{l}\text { 6. Early detection and controlling complications } \\
\text { efficiently. }\end{array}$ & 25 & 54.3 & 15 & 32.6 & 6 & 13.0 & 38 & 82.0 & 5 & 10.9 & 3 & 6.5 & 14.60 & $<0.001 * *$ \\
\hline $\begin{array}{l}\text { 7. Reassuring patients to stable emotional } \\
\text { condition and gaining patients cooperation when } \\
\text { implementing nursing interventions. }\end{array}$ & 17 & 37 & 24 & 52.2 & 5 & 10.9 & 33 & 71.7 & 9 & 19.6 & 4 & 8.7 & 10.648 & 0.033* \\
\hline $\begin{array}{l}\text { 8. Ensuring a gradual return to a normal diet and } \\
\text { preserving the desired body weight. }\end{array}$ & - & - & 27 & 58.7 & 19 & 41.3 & 40 & 87.0 & 6 & 13.0 & - & - & .215 & $0.043 *$ \\
\hline $\begin{array}{l}\text { 9. Improving patient comfort during } \\
\text { hospitalization and satisfying their demand. }\end{array}$ & 24 & 52.2 & 22 & 47.8 & - & - & 42 & 91.7 & 4 & 8.7 & - & - & 11.76 & 0.019* \\
\hline 10. Improving patients' activity daily living. & 10 & 21.7 & 25 & 54.3 & 11 & 23.9 & 33 & 70.2 & 10 & 21.3 & 4 & 8.5 & 10.75 & 0.039* \\
\hline $\begin{array}{l}\text { 11. Ensuring high level standard with isolation and } \\
\text { effective self-protective measure among patients. }\end{array}$ & 29 & 63.0 & 15 & 32.6 & 2 & 4.3 & 44 & 95.7 & 2 & 4.3 & - & - & 11.340 & $0.023 *$ \\
\hline
\end{tabular}

$N B$ : Significant $<0.05,{ }^{*}$ highly statistically significant at $\leq 0.001^{* *}$ 
Table (6): Distribution of the nurses' practice in elements of implementation pre/post application of adapting nursing process for COVID-19 isolated patients (n. $=46)$.

\begin{tabular}{|c|c|c|c|c|c|c|c|c|c|c|c|c|c|c|}
\hline \multirow{3}{*}{ The elements of Implementation } & \multicolumn{6}{|c|}{ Pre application of adapting nursing process } & \multicolumn{6}{|c|}{$\begin{array}{c}\text { post application of adapting nursing } \\
\text { process }\end{array}$} & \multirow{2}{*}{\multicolumn{2}{|c|}{ Significance test }} \\
\hline & \multicolumn{2}{|c|}{ always } & \multicolumn{2}{|c|}{ Sometimes } & \multicolumn{2}{|c|}{ Never } & \multicolumn{2}{|c|}{ always } & \multicolumn{2}{|c|}{ Sometimes } & \multicolumn{2}{|c|}{ Never } & & \\
\hline & $\mathbf{N}$ & $\%$ & $\mathbf{N}$ & $\%$ & $\mathbf{N}$ & $\%$ & $\mathbf{N}$ & $\%$ & $\mathbf{N}$ & $\%$ & $\mathbf{N}$ & $\%$ & $\mathbf{X}^{2}$ & P-value \\
\hline $\begin{array}{l}\text { 1. Providing optimal oxygen therapy and } \\
\text { respiratory care: }\end{array}$ & 30 & 65.2 & 16 & 34.8 & - & - & 39 & 84.8 & 7 & 15.2 & - & - & 39.26 & 0.592 \\
\hline 2. Maintaining a clear airway & 29 & 59.2 & 13 & 28.3 & 4 & 8.7 & 38 & 82.6 & 8 & 17.4 & - & - & 23.19 & 0.026 * \\
\hline 3. Nursing care for fever & 30 & 65.2 & 16 & 34.8 & - & - & 38 & 82.6 & 8 & 17.4 & - & - & 9.26 & 0.413 \\
\hline $\begin{array}{l}\text { 4. Special care for (blood purification treatment\& } \\
\text { convalescent plasma therapy). }\end{array}$ & 31 & 67.4 & 15 & 32.6 & - & - & 38 & 82.6 & 8 & 17.4 & - & - & 42.10 & $0.042 *$ \\
\hline 5. Monitoring and nursing for drug administration. & 27 & 58.7 & 19 & 41.3 & - & - & 36 & 78.3 & 10 & 21.7 & - & - & 70.26 & 0.469 \\
\hline 6. Nursing action for catheters. & 32 & 69.6 & 14 & 30.4 & - & - & 43 & 93.5 & 3 & 6.7 & - & - & 34.54 & 0.490 \\
\hline 7. Monitoring patients' conditions. & 14 & 30.4 & 32 & 69.3 & - & - & 36 & 78.3 & 10 & 21.7 & - & - & 59.77 & $0.010 *$ \\
\hline 8. Food and nutrition. & 29 & 63 & 17 & 37 & -- & - & 40 & 87 & 6 & 13 & - & - & 48.31 & $0.017 *$ \\
\hline $\begin{array}{l}\text { 9. Basic nursing care (skin care, elimination care } \\
\text { and oral care). }\end{array}$ & 14 & 30.4 & 32 & 74.4 & - & - & 36 & 78.3 & 10 & 21.7 & - & - & 98.73 & 0.736 \\
\hline 10. Patient psychological nursing care. & 14 & 30.4 & 32 & 69.6 & - & - & 34 & 73.9 & 12 & 26.1 & 2 & 4.3 & 26.62 & $0.046 *$ \\
\hline 11. Eerily respiratory rehabilitation. & 19 & 41.3 & 22 & 47.8 & 5 & 10.9 & 34 & 73.9 & 12 & 26.1 & - & - & 30.19 & $<0.001 * *$ \\
\hline 12. Rest and Physical activities. & 29 & 61.7 & 18 & 38.3 & - & - & 39 & 84.8 & 7 & 12.2 & - & - & 29.45 & $0.021 *$ \\
\hline 13. Discharge instructions. & 25 & 53.2 & 22 & 46.8 & - & - & 39 & 84.8 & 7 & 15.2 & - & - & 33.61 & $<0.05 *$ \\
\hline
\end{tabular}

$N B$ : Significant $<0.05, *$ highly statistically significant at $\leq 0.001 * *$ 
Table (7): Distribution of the nurses performance in elements of evaluation pre/post application of adapting nursing process for COVID-19 isolated patients (n. =46).

\begin{tabular}{|c|c|c|c|c|c|c|c|c|c|c|c|c|c|c|}
\hline \multirow{3}{*}{ The elements of Evaluation } & \multicolumn{6}{|c|}{ Pre application of adapting nursing process } & \multicolumn{6}{|c|}{$\begin{array}{c}\begin{array}{c}\text { post application of adapting nursing } \\
\text { process }\end{array} \\
\end{array}$} & \multirow{2}{*}{\multicolumn{2}{|c|}{ Significance test }} \\
\hline & \multicolumn{2}{|c|}{ always } & \multicolumn{2}{|c|}{ Sometimes } & \multicolumn{2}{|c|}{ Never } & \multicolumn{2}{|c|}{ always } & \multicolumn{2}{|c|}{ Sometimes } & \multicolumn{2}{|c|}{ Never } & & \\
\hline & $\mathbf{N}$ & $\%$ & $\mathbf{N}$ & $\%$ & $\mathbf{N}$ & $\%$ & $\mathbf{N}$ & $\%$ & $\mathbf{N}$ & $\%$ & $\mathbf{N}$ & $\%$ & $\mathbf{X}^{2}$ & P-value \\
\hline 1.Evaluating the patient health improvement & 25 & 54.3 & 12 & 22.3 & 9 & 19.6 & 37 & 80.4 & 8 & 12.9 & 1 & 2.2 & 11.11 & $0.025 *$ \\
\hline 2.Evaluating the application of nursing care plain & 20 & 43.5 & 26 & 56.5 & - & - & 39 & 84.8 & 7 & 15.2 & - & - & 7.71 & $0.021 *$ \\
\hline 3.Evaluating the nursing care from time to time & 9 & 19.6 & 27 & 58.7 & 10 & 21.7 & 32 & 69.6 & 8 & 17.4 & 6 & 13 & 13.33 & $<0.05 *$ \\
\hline 4.Evaluating nurse experience for nursing care & 19 & 39.6 & 16 & 34.8 & 11 & 23.9 & 35 & 76.1 & 9 & 19.6 & 2 & 4.3 & 5.140 & 0.273 \\
\hline 5.Evaluating the record all the nursing care steps & 17 & 37 & 29 & 63 & - & - & 37 & 80.4 & 9 & 19.6 & - & - & 7.47 & $0.033 *$ \\
\hline $\begin{array}{l}\text { 6. Evaluating the Patient was able to prevent the } \\
\text { spread of infection. }\end{array}$ & 31 & 67.4 & 15 & 32.6 & - & - & 42 & 91.3 & 4 & 8.7 & - & - & 2.337 & 0.311 \\
\hline $\begin{array}{l}\text { 7. Evaluating the Patient was able to learn more } \\
\text { about the disease and its management. }\end{array}$ & 31 & 67.4 & 15 & 32.6 & - & - & 38 & 82.6 & 8 & 17.4 & - & - & 11.033 & $0.026 *$ \\
\hline $\begin{array}{l}\text { 8. Evaluating the Patient was able to improve body } \\
\text { temperature levels. }\end{array}$ & 19 & 41.3 & 25 & 54.3 & 2 & 4.3 & 39 & 84.8 & 6 & 13 & 1 & 2.2 & 12.02 & $<0.05 *$ \\
\hline $\begin{array}{l}\text { 9. Evaluating the Patient was able to restore } \\
\text { breathing pattern back to normal. }\end{array}$ & 31 & 67.4 & 15 & 32.6 & - & - & 40 & 87.0 & 6 & 13 & - & - & 1.035 & 0.596 \\
\hline $\begin{array}{l}\text { 10. Evaluating the Patient was able to reduce } \\
\text { anxiety. }\end{array}$ & 17 & 73.0 & 18 & 39.1 & 11 & 23.6 & 34 & 73.9 & 7 & 15.2 & 5 & 10.9 & 6.83 & $0.030 *$ \\
\hline 11. Evaluating the Teaching plan. & 21 & 45.7 & 16 & 34.8 & 9 & 19.6 & 35 & 76.1 & 8 & 17.4 & 3 & 6.5 & 5.61 & $<0.05 *$ \\
\hline
\end{tabular}

NB: Significant $<0.05, *$ highly statistically significant at $\leq 0.001 * *$. 
Table (8): Total distribution of the studied nurses' practice regarding pre/post application of adapting nursing process for COVID-19 isolated patients $(n .=46)$

\begin{tabular}{|c|c|c|c|c|c|c|c|c|c|c|c|c|c|c|}
\hline \multirow{3}{*}{$\begin{array}{c}\text { Total Nursing } \\
\text { process Component }\end{array}$} & \multicolumn{6}{|c|}{$\begin{array}{c}\text { Pre application of adapting nursing } \\
\text { process }\end{array}$} & \multicolumn{6}{|c|}{$\begin{array}{c}\text { post application of adapting } \\
\text { nursing process } \\
\end{array}$} & \multirow{2}{*}{\multicolumn{2}{|c|}{ Significance test }} \\
\hline & \multicolumn{2}{|c|}{ always } & \multicolumn{2}{|c|}{\begin{tabular}{|c|} 
Sometimes \\
\end{tabular}} & \multicolumn{2}{|c|}{ Never } & \multicolumn{2}{|c|}{ always } & \multicolumn{2}{|c|}{ Sometimes } & \multicolumn{2}{|c|}{ Never } & & \\
\hline & $\mathbf{N}$ & $\%$ & $\mathbf{N}$ & $\%$ & $\mathbf{N}$ & $\%$ & $\mathbf{N}$ & $\%$ & $\mathbf{N}$ & $\%$ & $\mathbf{N}$ & $\%$ & $\mathrm{X}^{2}$ & P-value \\
\hline Assessment & 20 & 60.6 & 13 & 39.4 & - & - & 44 & 93.4 & 3 & 6.4 & - & - & 28.476 & $<.001 * *$ \\
\hline Diagnosis & 8 & 17 & 33 & 70.2 & 6 & 12.8 & 38 & 80.9 & 8 & 17 & 1 & 2.1 & 160.11 & $<.001 * *$ \\
\hline Planning & 17 & 36.2 & 30 & 63.8 & - & - & 42 & 89.4 & 5 & 10.6 & - & - & 64.98 & $<.001 * *$ \\
\hline Implementation & 21 & 45.7 & 19 & 41.3 & 6 & 13.4 & 41 & 89.1 & 3 & 6.5 & 2 & 4.3 & 40.46 & $<.001 * *$ \\
\hline Evaluation & 10 & 30.3 & 23 & 69.7 & - & - & 42 & 91.3 & 4 & 8.7 & - & - & 109.98 & $<.001 * *$ \\
\hline
\end{tabular}

NB: Significant $<0.05$, *highly statistically significant at $\leq 0.001 * *$.

Table (9): Correlation between total component of nursing process and total knowledge post application of adapting nursing process for COVID-19 isolated patients (n. $=46)$.

\begin{tabular}{|c|c|c|}
\hline Variables & \multicolumn{2}{|c|}{ Total Knowledge } \\
\cline { 3 - 3 } & $\mathrm{r}$ & P-value \\
\hline Total component of Nursing process & 0.849 & $<0.029$ \\
\hline
\end{tabular}

NB: Significant $<0.05,{ }^{*}$ highly statistically significant at $\leq 0.001 * *$.

Table (1): This table shows that, socio-demographic characteristics of the studied nurses, there were more than half of them age group between $26<30$ years, (63\%) from the study females. (69.8\%) No training on application of nursing process, (52.2\%) have experience from 5-10 Years, however (52.2\%) have institute education, (54.3\%) working in ICU, (56.5\%) work at Day shafting.

Table (2): Illustrated that three quarters of the study sample (73.9\%) had satisfactory level of knowledge pre adapting nursing process, with all study sample $(100 \%)$ had satisfactory post application nursing process with highly significant difference $(\mathrm{P}<0.001)$. Table (3): This table illustrates that, the statistical significant differences in nurses' practice between the elements of assessment pre /post application of nursing process for COVID-19 isolated patients. Table (4): This table illustrates that, the statistical significant differences in nurses' practice between the elements of diagnosis pre /post application of nursing process for COVID-19 isolated patients.

Table (5): This table illustrates that, the statistical significant differences in nurses' practice between the elements of planning pre /post application of nursing process for COVID-19 isolated patients.

Table (6): This table denotes that, the statistical significant differences in nurses practice between the elements of implementation pre /post application of nursing process for COVID-19 isolated patients. Table (7): This table illustrates that, the statistical significant differences in nurses' practice between the elements of evaluation pre /post application of nursing process for COVID-19 isolated patients.
Table (8) :This table denotes that, the highly significant results for total component of nursing process (assessment, diagnosis, planning, implementation, evaluation) at $(\mathrm{P}<0.01)$ pre/post adapting application of nursing process for COVID19 isolated patients.

Table (9): This table denotes that, positive correlation between total components of nursing process and total knowledge post adapting application of nursing process for COVID-19 isolated patients with statistical significance $(\mathrm{P}<0.001)$.

\section{Discussion}

The nursing process is a scientific and problem solving method used by nurses to ensure the quality of patient care. This method used to develop evidence-based plans for patients with COVID-19, as they respond to actual or potential health problems. The nursing process accepted as a care standard with the stages of assessment, nursing diagnosis, planning, implementation and evaluation as the five steps of the patient care (Ravnskow, 2020).

This study aimed to evaluate the effect of adapting (NANDA) nursing process as an approach of care on nurses' performance for COVID-19 isolated patients. As regarding demographic characteristics of the current study showed that, more than half of the study age group between $26<30$ years, females, no training on application of nursing process, half of them have experience from 5-10 Years, institute education. This result is contradicting with Natheer, (2019), who study about "assessments of the 
application of nursing process, with the age group 35-39 years" with respect, majority of the participants were females while 48 (24.0) \% for their years of experience, $62(31.0 \%)$ had up to four years of experience, the majority, 140 (70) \% of the respondents acquired their educational award from government institutions.

As regarding to knowledge score of nurses', there was significance difference $(\mathrm{P}<0.001)$ between pre/post application of (NANDA) nursing process which indicate improvement of total knowledge regarding COVID-19.

The level of pretest nurses knowledge of the majority of studied sample generally was unsatisfactory. This might be related to the lack of knowledge and that most of them were not received any previous training and courses about care of COVID-19 patients by steps of nursing process. This lack of knowledge may be also due to increased work load which may hinder nurses' ability to read and update their knowledge. Thus, there was a need to strengthen what nurses know and provide them with the needed knowledge necessary to improve their practice and so, patient' care.

This result was supported by Hagos, (2014), who study" Application of Nursing Process and Its Affecting Factors among Nurses Working in Mekelle Zone Hospitals "Showed among the educational status has a statically significant relationship with knowledge of nurses on nursing process that post application has better knowledge than pre application.

Adapting of statement application by using steps of (NANDA) nursing process for COVID-19 in crises situation, on key areas namely assessment, diagnosis, planning, implementation, and evaluation revealed various levels of competencies.

Generally, the study revealed an average level of adequacy of these assessed areas, since the respondents reported adequate competency in three of the areas (assessment, diagnosis and planning) the significant results for statement assessment at $(\mathrm{P}<$ 0.001) pre/post application. Assess the patient's history of living in the epidemic area, family history of the diseases, past medical history, treatment history, epidemiological history, and comorbidities, etc.

This finding agreed with Nurses United, (2020), who study "emergency assessment nurses will continue to be at the front line of patient care in hospitals and closely involved with assessment and monitoring in COVID-19" Reported that they must ensure that all patients receive individualized, high-quality care regardless of their infection status and participate in preparation for increased nursing and health system demand related to COVID-19.
As regards the nurses who are working with COVID19 patients, regarding statement diagnosis the significant results for pre/post application of nursing process. The results of the present study were on the same line with World Health Organization, (2019), study about "clinical nursing care and nursing diagnosis" Recommended that the nurse must be have early detection of problems and guide nursing care for patients with COVID-19 in severe and critical condition and to effectively preserve their physical and mental health.

As regards the nurses working with COVID-19 patients, regarding statement planning the significant results for pre/post application of nursing process. The results of the present study were on the same line with Xie, (2020), who study about" Critical care crisis and some recommendations during the COVID19 epidemic " which reported that, to apply the planning care for patient with coved 19, used nursing process in practice it requires nurses' competency and training about how to managing emergency situation, need adequate time, nursing human power and materials.

According to Wu, (2019), declared in their study about " Characteristics of and important lessons from the coronavirus disease 2019 (COVID-19) outbreak " stated that in the Emergency Department, nurses often encounter to emergency and critically ill patients. The instinct of many emergency nurses, in particular, is to run towards a critically ill patient and initiate planning care and treatment. It is important that nurses and other healthcare workers take a treating how to apply appropriate personal protective equipment prior to any resuscitation. This is supported by interim guidance from the American Heart Association. Jansson, (2010), addresses "Factors and Conditions that Influence the Implementation of Standardized Nursing Care Plans" showed that nurses must care for themselves in order to be healthy and available to care for future patients Also current result is in the same line with the study conducted by International Council of Nurses, (2020), Stated that nursing process provides comprehensive guidance on the management of the emergency and critically ill patients.in response to the pandemic outbreak of coronavirus disease (COVID19). Also agreed with American Nurses Association, (2009), study "The Nursing Process: A Common Thread among all Nurses" which reported postulates that NP is an important framework that needs to be practiced by nurses in providing high quality standard of care in all isolated hospital caring patient with coved 19. According to World Health Organization, (2019), uses a checklist to assess the practice implementation of the nursing process within 
the facility by evaluating the files of in-patients hospitalized at the time of the study. The study indicates the nurses working with COVID-19 patients, regarding statement implementation the significant results for pre/post application of nursing process.

As regards to the nurses who are working with COVID-19 patients, regarding statement of implementation the significant results for pre/post application of nursing process, this result agreed with Rajabpooret, et al., (2018) the implementation of this process increases patients' satisfaction due to an improves the quality of nursing care and documentation, it saves time, nursing errors are reduced and increase in patient-nurse communication. Nurses had good practice in some items pre and post application of nursing process. This could reflect nurses' familiarity with certain basic aspects of care for patients' with coronavirus disease (COVID-19). Also was on the same line with the study conducted by Mahmoud, \& Bayoumy, (2014) addressing "Barriers and Facilitators for Execution of Nursing Process from Nurses' perspective" stated that furthermore, the nursing process help the staff nursing to focus of forecast essential supplies: it includes estimation of personal protective equipment, diagnostic equipment, biomedical equipment for case management, essential drugs for supportive care, and consumable medical supplies.

Also may be relevant to nurses' practices were based on traditions. Even though the frequency of application of nursing process, there were limited data related to the nursing care guidelines for patients with coronavirus disease (COVID-19) This, agreed with Birhanu, et al., (2010), declared in their study about " Determinants of satisfaction with health care provider interactions " reported that the Chinese Government has proposed establishing a holistic nursing care for severe and critical patients to rapid assessment, diagnosis, raped nursing intervention to prevent complications. Also, provide patient centered care following modern nursing concepts, and utilizing nursing procedures as nursing process based on fundamental framework and guide for care.

The current study showed that, there was a highly statistical significant positive correlation between the nurses' knowledge and practices pre/post application of steps of nursing process. This study in line with Semachew, (2018), study about "Implementation of nursing process in clinical settings" \& Zamanzadeh, et al., (2015), systematic review about "Challenges associated with the implementation of the nursing process" which reported Clinical experience and research evidence so far suggest that caring emergency patient by using steps of nursing process conceder of key components of good supportive care include oxygenation; management of symptoms, fluid balance, and chronic conditions; multidisciplinary management among hospital medicine, infectious diseases, pulmonary critical care, increase patient recovery rate and decrease lengths of hospital stay .

The current study answered the research hypothesis. So the developed statement of nursing care in the form of steps of nursing process affect positively on the nurses' competency level, knowledge and practices.

\section{Conclusions}

Based on the findings of the current study, it can be concluded that: Adapting of (NANDA) Nursing Process as an Approach of Care for COVID-19 isolated patients was improved the level of nurses' knowledge post caring for COVID-19 isolated patients by using steps of nursing process with high significant difference between pre and post the study. In addition, there was highly statistical significant deference's for total components of nursing process assessment, diagnosis, planning, implementation, and evaluation.

\section{Recommendations}

1. The nursing staff and health care team must continue education on how to apply the nursing process at emergency situations.

2. Nursing administration should develop effective departmental policies and procedures for staff nurses related to application of (NANDA) nursing process as an approach of care for COVID-19 isolated patients.

3. Further study with replication of the current study on a larger probability sample is recommended to achieve generalization of the results.

4. Provision of in-service training on regular basis in order to update and refresh practice related to care for COVID-19 isolated patients.

\section{References}

- American Nurses Association. (2009): The Nursing Process: A Common Thread among all Nurses. From http://www.nursing world.org. Accessed online on 27/06/2017.

- American Nurses Association, (2020): Coronavirus disease (COVID-19). https://www.nursing world.org/practicepolicy/work-environment/health - safety/disasterpreparedness/coronavirus.

- American Society of Anesthesiologists, (2020): Practice guidelines for central venous access 2020: an updated report by the American Society of 
Anesthesiologists task force on central venous access. Anesthesiology 2020;132:8e43.

- Birhanu, Z., Assefa, M., Woldie, T., \& Morankar, (2010) :Determinants of satisfaction with health care provider interactions at health centres in central Ethiopia :a cross sectional study," BMC Health Services Research, vol .10, article 78, 2010.

- Chen W., (2020): Clinical application of nutritional dietary guidelines for the prevention and treatment of novel coronavirus-infected pneumonia. Beijing Med J 2020 Feb 19.

- Chinese Preventive Medicine Association, (2020): Expert group on the prevention and control of novel coronavirus pneumonia. Latest understanding of epidemiological characteristics of novel coronavirus pneumonia. Chin J Vir Dis 2020 Feb 24. https://doi.org/10.16505/j.20950136.2020.0015. Epub.

- Chinese Health Education Center, National Health Commission Ministry of Publicity, (2020): Health education manual for novel coronavirus-infected pneumonia Available from: http://www.gov.cn/fuwu/2020-

02/10/content_5476794.htm.

- Committee of Critical Care Medicine, Chinese Association of Chest Physician, Chinese Medical Doctor Association, Critical Care Medicine Group, Chinese Thoracic Society, Chinese Medical Association. (2019): [Recommendations for clinical application of extracorporeal membrane oxygenation in adults severe respiratory failure]. Chin J Tuberc Respir Dis 2019;42:660e84.

- Dong, E., Du, H., \& Gardner L., (2020): An interactive web-based dashboard to track COVID19 in real time. Lancet Infect Dis 2020. Accessed on: 14th July 2020.

- Expert Team of Chinese Medical Association Nephrology Branch, (2020): Recommendations for prevention and control of novel coronavirus infection in blood purification center (room) from the Chinese Medical Association Nephrology Branch]. Chin J Nephrol 2020;36:82e4.

- Ge H., Dai, B., Xu P., Duan, K., Xia, J., \& Duan J., (2020): Expert consensus on the sensory management of ventilator use in patients with novel coronavirus pneumonia. Writing Committee Members / International Journal of Nursing Sciences 7 (2020) 128e134 133 Chin J Respir Crit Care Med 2020;19:116e9.

- Hagos, F., Alemseged, F., Balcha, F., Berhe, S., \& Alemseged Aregay, (2014) : Application of Nursing Process and Its Affecting Factors among Nurses Working in Mekelle Zone Hospitals, Northern Ethiopia. Hindawi Publishing
Corporation. Nursing Research and Practice. Volume 2014, Article ID 675212, 9 pages.http://dx.doi.org/10.1155/2014/675212.

- Infectious Diseases Group of the Respiratory Medicine Branch of the Chinese Medical Association, (2018): Diagnosis and treatment guidelines for hospital-acquired pneumonia and ventilator-related pneumonia in Chinese adults . Chin J Tuberc Respir Dis 2018;41(4):255e80.

- International Council of Nurses, (2020): ICN sends message of support to nurses in China and elsewhere who are tackling Coronavirus. https://www.icn.ch/news/icn-sends -messagesupport-nurse s-china -and elsewhere-who-aretackling-coronavirus.

- Jansson, I., Bahtsevani, C., PilhammarAndersson, E., \& Forsberg, A., (2010): Factors and Conditions that Influence the Implementation of Standardized Nursing Care Plans. The open nursing journal, 4, 25-34.

- Jin , Y., Cai , L., Cheng, Z., Cheng, H., Deng, T., \& Fan, Y., (2020): Quick guide to the diagnosis and treatment of novel coronavirus (2019-nCoV) pneumonia (standard version). Med J Chin People Lib Army 2020;45(1):120.

- Karttunen, M., Sneck, S., Jokelainen, J., \& Elo, S., (2020 ): Nurses' self-assessments of adherence to guidelines on safe medication preparation and administration in long-term elderly care. Scand J Caring Sci. 2020 Mar;34(1):108-117. [PubMed].

- Martin, J., \& Bowden N., (2020): Drug repurposing in the era of COVID-19: a call for leadership and government investment. Med J Aust. 2020;212:450-452.

- Miskir, Y., \& Emishaw, (2018): Determinants of Nursing Process Implementation in North East Ethiopia: Cross-Sectional Study. Nursing research and practice, 2018. 2018. In 1958, Ida Jean Orlando started the nursing process that still guides nursing.

- Mahmoud, M., \& Bayoumy, H., (2014): Barriers and Facilitators for Execution of Nursing Process from Nurses' perspective. International Journal of Advanced Research, 2014. 2(2): p. 300-315.

- Ma J., Hu F., Sun H., Chen J., Ding X., \& Li J., (2020): Nursing experience of treating a critical ill patient with novel coronavirus (2019-nCoV) infected pneumonia by using ECMO. J New Med 2020;30:74e7.

- Natheer, M., (2019): Assessment of the application of nursing process in surgical words. Mosul Journal of Nursing, Vol.7, No.1, 2019

- National Health Commission of the People's Republic of China. (2020): Diagnosis and treatment schemes for severe novel coronavirusinfected pneumonia cases (trial) [Internet]. 
Available

http://www.nhc.gov.cn/yzygj/s7653p .

- National Health Commission of the People's Republic of China.(2020): Announcement of the national health commission of the People's Republic of China, vol. 1;2020 Available from:http://www.nhc.gov.cn/jkj/s7916/202001/44a 3b8245e8049d2837a4f27529cd386.shtml.

- Ni Z., Qin H., Li J., Wang Q., Wang J., \& Jing G., (2020): Expert consensus on the management of nasal high-flow oxygen therapy in patients with novel coronavirus pneumonia. Chin J Respir Crit Care Med 2020;19:110e5.

- Nurses United (2020): National Nurses United Response to COVID-19. https://www.natio nalnu rsesu nited.org/covid -19 .

- Raso, A., Ligozzi, L., Garrino, L., \& Dimonte, V., (2019): Nursing profession and nurses' contribution to nursing education as seen through students' eyes: A qualitative study. Nurs Forum. 2019 Jul;54(3):414-424.

- Ravnskow, U., (2020): Cholesterol-lowering treatment may worsen the outcome of a Covid19infection. BMJ 2020;368:m1182.

- Respiratory Critical Care Medicine Group of the Respiratory Medicine Branch of the Chinese Medical Association, Critical Care Medicine Working Committee of the Respiratory Medicine Branch of the Chinese Medical Doctor Association (2020): Airway management recommendations for adults with severe novel coronavirus pneumonia (trial). Natl Med J China 2020;100:E004.

- Regulation for washing and disinfection technique of medical textiles in healthcare facilities, (2016): Chin J Infect Control 2016;16(7):687e92.

- Rajabpoor, M., Zarifnejad, G., Mohsenizadeh, S., Mazloum, S., Pourghaznein, T., Mashmoul, A., \& Mohammad, A., (2018): Barriers to the implementation of nursing process from the viewpoint of faculty members, nursing managers, nurses and nursing students. Journal of Holistic Nursing and Midwifery, 28(2), 137- 142. https://doi.org/10.29252/hnmj.28.2.137.

- Semachew, A., (2018): Implementation of nursing process in clinical settings: The case of three governmental hospitals in Ethiopia, 2017. BMC Research Notes, 11(1), 173. https://doi.org/10.1186/s13104-018-3275-z.

- Tan, H., Chen, Y., Chen, S., Mo H., Li X., \& Tang, X., (2017): Development and application of fall prevention process management among hospitalized patients. Chin Nurs Manag 2017;17:818e21.
- Tongji Hospital Affiliated with Tongji Medical College of Huazhong University of Science \& Technology, (2020): Novel Coronavirus Pneumonia Treatment Collaboration Group. Consensus on the diagnosis and management of severe novel coronavirus pneumonia cases [Internet]. Available from: http://health.people. com.cn/n1/2020/0211/c14739-31581678.html.

- Wang, C., Fang, F., Xie, Y., Zhao, H., \& Yu P., (2019): Guidelines for respiratory rehabilitation of patients with 2019 novel coronavirus pneumonia (first edition). Chin J Reparative Reconstr Surg 2020;34(3):275e9.

- Wang, H., Zeng, T., Xinjuan, W., \& Sun, H., (2019): Holistic care for patients with severe coronavirus disease : An expert consensus International Journal of Nursing Sciences journal homepage: http://www.elsevier.com/journals/internationaljournal-ofnursing-sciences/2352-0132.

- Wang, Q., Jing, X., Zhu Z., Zheng, J., Kong, R., \& Zhang X., (2020): Discussions on key infection prevention and control issues of ventilator use in novel coronavirus pneumonia patients under mechanical ventilation. Chin J Infect Dis 2020;38: E005.

- World Health Organization. Novel coronavirus (2019-nCoV) situation report -12 . Available from: https://www.who.int/docs/default-source/ coronaviruse/situation-reports/2020-0201-sitrep12-ncov.pdf. sfvrsn $1 / 4273 \mathrm{c} 5 \mathrm{~d} 35 \_2$.

- World Health Organization, (2020): Coronavirus disease (COVID-19) outbreak. https://www.who.int/emergencies/diseases/novelcoron avirus-2019.

- World Health Organization, (2020): Infection prevention and control during health care when novel coronavirus (nCoV) infection is suspected. Available from: https://www.who.int/publicationsdetail/infection-prevention-and-controlduringhealth-care-when-novel-coronavirus-(ncov)infection-is-suspected-20200125.

- Wu Z., \& Mcgoogan, J., (2019): Characteristics of and important lessons from the coronavirus disease 2019 (covid-19) outbreak in China: summary of a report of 72314 cases from the Chinese Center for Disease Control and Prevention. JAMA 2020;323:1239-42. 10.1001/jama.2020.2648 32091533

- Xie, J., Tong, Z., Guan, X., Du B., Qiu H., \& Slutsky A., (2020): Critical care crisis and some recommendations during the COVID-19 epidemic in China. Intensive Care Med. 2020;46(5):837840.

- Xu, J., Zeng, F., Wu Y., Zhou T., Han Y., \& Lu Y., (2020): Nutritional support and monitoring 
recommendations for patients with severe novel coronavirusinfected pneumonia. Epub Chin J Hosp Pharm 2020;40(5):1e3. Availablefrom:http://kns.cnki.net/kcms/detail/42.1 204.r.20200218.0954.002.html.

- Younan, L., Clinton, M., Fares, S., \& Samaha H., (2019): The translation and cultural adaptation validity of the Actual Scope of Practice Questionnaire. East. Mediterr. Health J. 2019 Apr 25;25(3):181-188. [PubMed].

- Zamanzadeh, V., Valizadeh, L., Jabbarzadeh-Tabrizi, F., Behshid, M., \& Lotfi, M., (2015): Challenges associated with the implementation of the nursing process: A systematic review. Iranian Journal of Nursing and Midwifery Research, 20(4), 411- 419. https//:doi.org/10.4103/1735-9066.161002. 